\title{
Interrelation between Cloud Computing Technology and Agriculture Fields
}

\author{
Deepak Indoria $^{1}$ and Deepa Indoria ${ }^{2 *}$ \\ ${ }^{1}$ Yagvalkya Institute of Technology, RTU, Kota, Rajasthan, India \\ ${ }^{2}$ Krishi Vigyan Kendra, Chittorgarh, Rajasthan, India \\ *Corresponding author
}

\section{Key w ords \\ Cloud computing, Community model, Hybrid model, Public model, Private model, Agriculture, IaaS, Paas \& SaaS \\ Article Info \\ Accepted: 20 December 2018 Available Online: 10 January 2019}

\section{A B S T R A C T}

Cloud computing is an architecture for facilitating computing service through the internet on requirement and pay per user access to a group of shared resources namely networks, storage, servers, services and applications, without physically acquiring them Cloud DBMS is a distributed database that gives computing as a service. It is sharing of web infrastructure for resources, software and information over a network. The cloud is used as a storage location and database can be accessed and computed from anywhere. In this paper I have discussed about cloud and its use. How we can implement cloud for better performance and different benefits and drawbacks of cloud which we can improve in future Use of Cloud computing technology in agricultural areas has greater chance in the overall development of India. An effective implementation of cloud computing is encouraging in agricultural sector. Cloud Computing is emerging today as a commercial infrastructure that eliminates the need for maintaining expensive computing hardware, software, Information technology, staff, infrastructure, recourses and their maintenance. Cloud computing is a network-based environment that focuses on sharing computations, Cloud computing networks access to a shared pool of configurable networks, servers, storage, service, applications \& other important computing resources. In modern era of cloud computing technology very helpful for centralized the all-agricultural related data bank (Soil-related, weather, Research, Crop, Farmers, Agriculture marketing, fertilizers and pesticide information) in the cloud. In this paper, also discuss Computing model, characteristics, deployment model, cloud service model, cloud benefits and challenge of cloud computing in agriculture field.

\section{Introduction}

Cloud computing is the provision of computer or IT infrastructure through the Internet. That is the provisioning of shared resources, software, applications and services over the internet to meet the elastic demand of the customer with minimum effort or interaction with the service provider. India is one of the largest producers of foods, grains and other products, but still agriculture and its production process are decentralized, unsophisticated and outdated methods being followed by the farmers, together with several constraints of the farmers and modernization is very slow. This results in an obvious gap between the supply and demand chains of the agricultural products. This will have a 
negative impact on the farmer's economic conditions as well the national income of the country. This bottleneck can be eliminated with the implementation of Cloud Computing facility in agricultural field. The centralized location has to be set up to store all the relevant data. It can include various, Separate databases Soil-related, weather-related, Research, Crop and Farmers-related data can all be stored at a single location, and data availability can be achieved. This data can be accessed by the end-users such as farmers, experts, consultants, researchers etc easily any time from any location through the devices that are connected to the cloud system (Fig. 1).

\section{Computing models}

\section{Desktop computing}

This type of computing used in single PC Computing. This types of computing facility applicable for personal, Professional (Engineer, artist, authors, doctors, programmers) office and publishing house (Fig. 2).

\section{Client server computing}

Client server computing is a system that performs both the functions of client and server to promote the sharing of information between them. A Client is any process that requests specific services from the server process. A Server is a process that provides requested services for the Client. it allows many users to have access to the same database at the same time, and the database will store much information. Various types of server used in Clint service computing such as mail server, file server, fax server, database server, web server. Example of client server System, File transfer: This is the transmission of files between the client and server. It also allows storing of files on the server. Files such as movies, images, music can be stored (Fig. 3).

\section{Cluster computing}

In cluster computing, a group of similar computers is hooked up locally to operate as a single compute. This facility utilized for load balance of servers. Main advantages of this computer technology is distributed the load of server among the each servers of computer (Fig. 4).

\section{Grid computing}

Grid computing is the collection computers resources from multiple locations to reach a common goal (Fig. 5).

Benefits of grid computing are Increase access to data and collaboration, join data and distribute it globally, Support large multidisciplinary collaboration, Workload balance, data security etc. Main characteristics of grid computing listed in the below:

Grid coordinates Resources that are not subjected to centralized control.

Grid use standard, open, general-purpose protocols and interfaces.

Grid deliver high quality of Service

\section{Cloud computing}

Cloud computing is the combination of cluster and grid computing. The IT environment evolved from mainframes to client servers, the Internet, virtualization and cloud computing.

Cloud computing provides a shared pool of configurable IT resources (e.g. processing, network, software, information and storage) on demand, as a scalable and elastic service, through a networked infrastructure, on a measured (pay-per-use or subscription) basis, which needs minimal management effort, is based on service level agreements between the service provider and consumers, and often utilizes virtualization resources (Fig. 6). 


\section{Characteristics of cloud computing}

On-demand self-service: A consumer can unilaterally provision computing capabilities, such as server time and network storage, as needed automatically without requiring human interaction with each service provider.

Broad network access: Capabilities are available over the network and accessed through standard mechanisms that promote use by heterogeneous thin or thick client platforms (e.g., mobile phones, tablets, laptops, and workstations).

Rapid elasticity: Cloud services can be rapidly and elastically provisioned, in some cases automatically, to quickly scale out and rapidly released to quickly scale in. To the consumer, the capabilities available for provisioning often appear to be unlimited and can be purchased in any quantity at any time.

Measured service: Pay per use-capabilities is charged using a metered, fee-for-service, or advertising based billing model to promote optimization of resource use. Examples are measuring the storage, bandwidth and computing resources consumed and charging for the number of active user accounts per month.

Resource pooling: The provider is computing resources are pooled to serve multiple consumers using a multi-tenant model, with different physical and virtual resources dynamically assigned and reassigned according to consumer demand.

There is a sense of location independence in that the customer generally has no control or knowledge over the exact location of the provided resources but may be able to specify location at a higher level of virtuosity (e.g., country, state, or data center). Examples of resources include storage, processing, memory, network bandwidth, and virtual machines.

\section{Deployment model of cloud computing}

\section{Public cloud}

The cloud infrastructure applications, storage, and other resources are made available to the public for free or on pay-per-use model (Fig. 7). It is owned by an organization selling cloud services. Example: Amazon, Google Apps, Windows Azure etc.

Some Important point for Public Cloud

Entirely hosted by External Providers

Almost any customer can pay for resource on the cloud.

Support is handling by the provider.

\section{Community cloud}

The cloud shares infrastructure for specific community with common concerns (security, compliance, jurisdiction etc), whether managed internally or by a third party and hosted internally or externally.

\section{Hybrid cloud}

The cloud infrastructure is a composition of two or more clouds (private, community, or public) that re-main unique entities but are bound together by standardized or proprietary technology that enables data and application portability.

\section{Private cloud}

The cloud infrastructure is operated solely for a single organization. It may be owned, managed and operated by the organization or a third party, and may exist on-premises or offpremises. 


\section{Model of cloud computing}

\section{SaaS (Software as a service) model}

Through this service delivery, model end users use the software application services directly over network according to on-demand basis. In this type, service only required administrator and cloud consultants. Example sales force, drop box and Google applications such as Email, Google drive, talk etc (Fig. 8).

\section{PaaS (Platform as a service) model}

In the PaaS model, cloud providers deliver a computing platform, typically including operating system, programming language execution environment, database, and web server. This type service only software developer required for deployment of software, Example Google application engine, window Azure, force.com etc.

\section{Infrastructure as a service (IaaS)}

In an IaaS model, resources can easily be scaled up, depending upon the demand from the user, services being charged in a pay-per use model. Network administrator and programmer required for Iaas services, Example Amazon web service, IBM, HP etc.

Role of cloud computing in agriculture field (rural and hills)

Agriculture information data bank (crop, weather, soil, growth progress, farmer data and expert consultation)

Store all the agriculture related information in a centralized cloud, which will be available to all the users at anytime, anywhere

Management of all data related to land, location, area; soil and land characteristics through centralized decision support systems High integration and sharing of agricultural information

It can be eliminate the farmer's limitations of technical knowledge and resources

Providing agricultural technology service and science

Improvement of the agricultural products marketing Efficient use of agricultural resources

Promote the circulation of agricultural product and service in wider level.

Fig.1 Agriculture cloud system

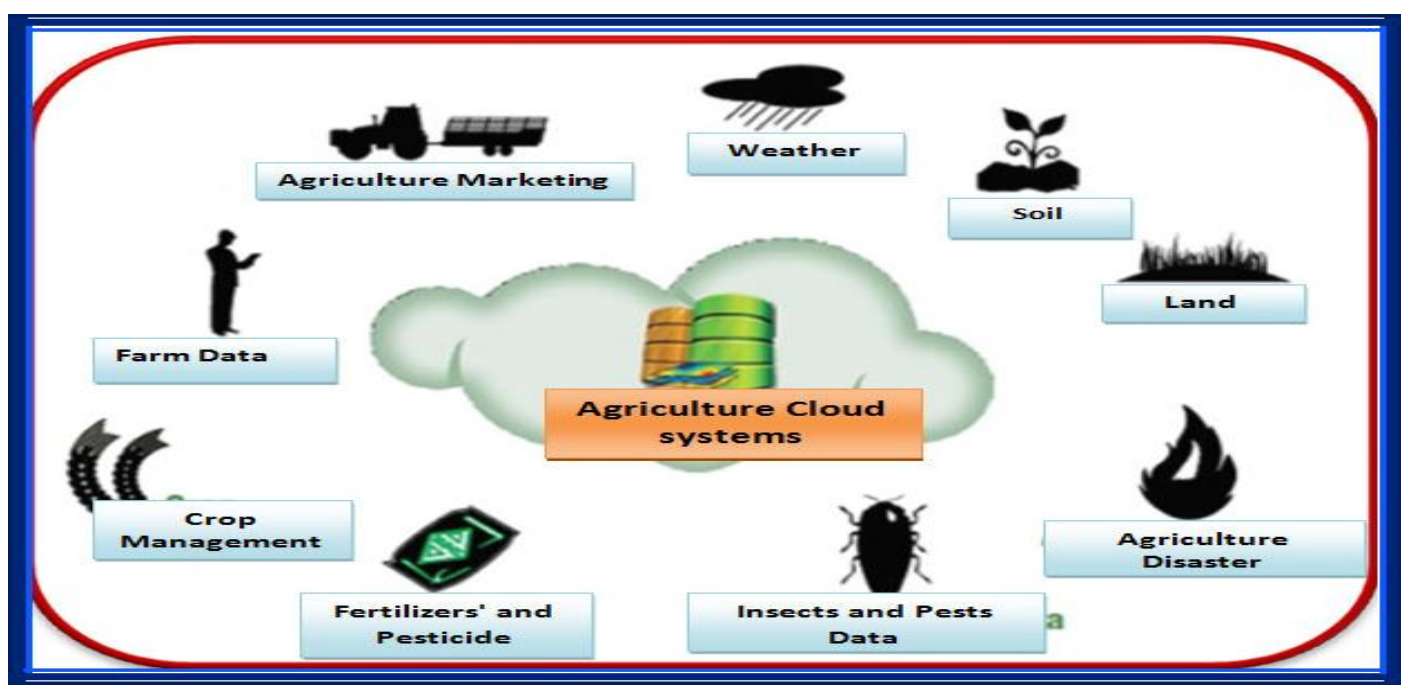


Fig.2 Desktop computing

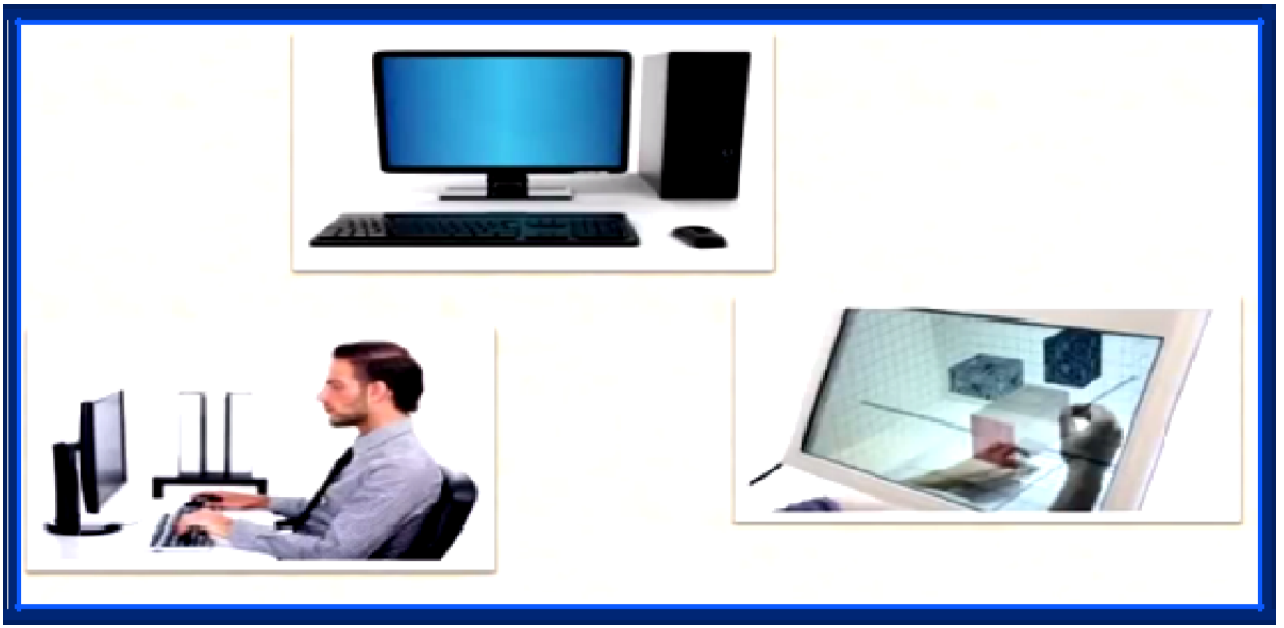

Fig.3 Clint server Computing

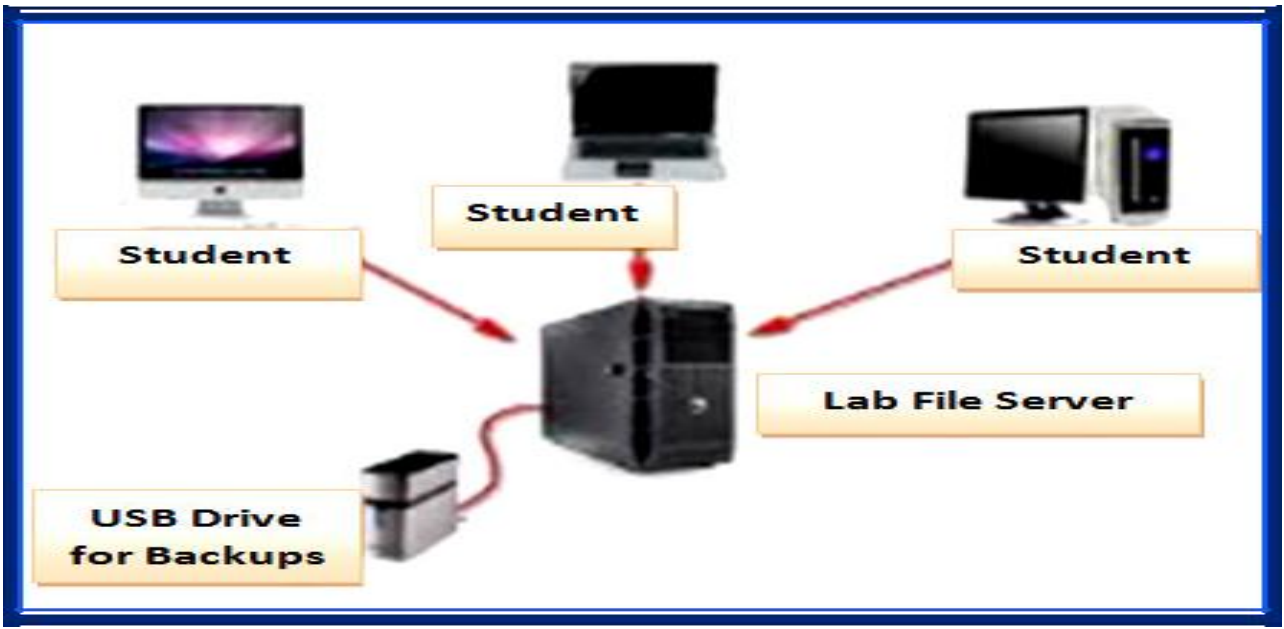

Fig.4 Cluster computing

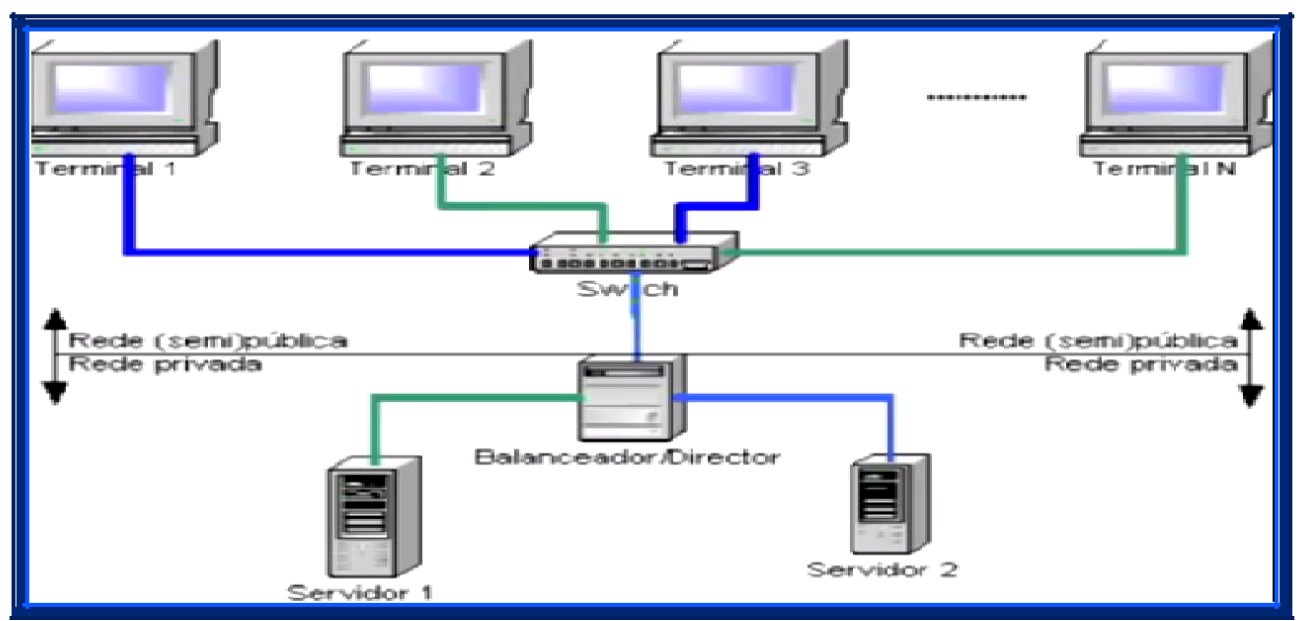


Fig.5 Grid computing.

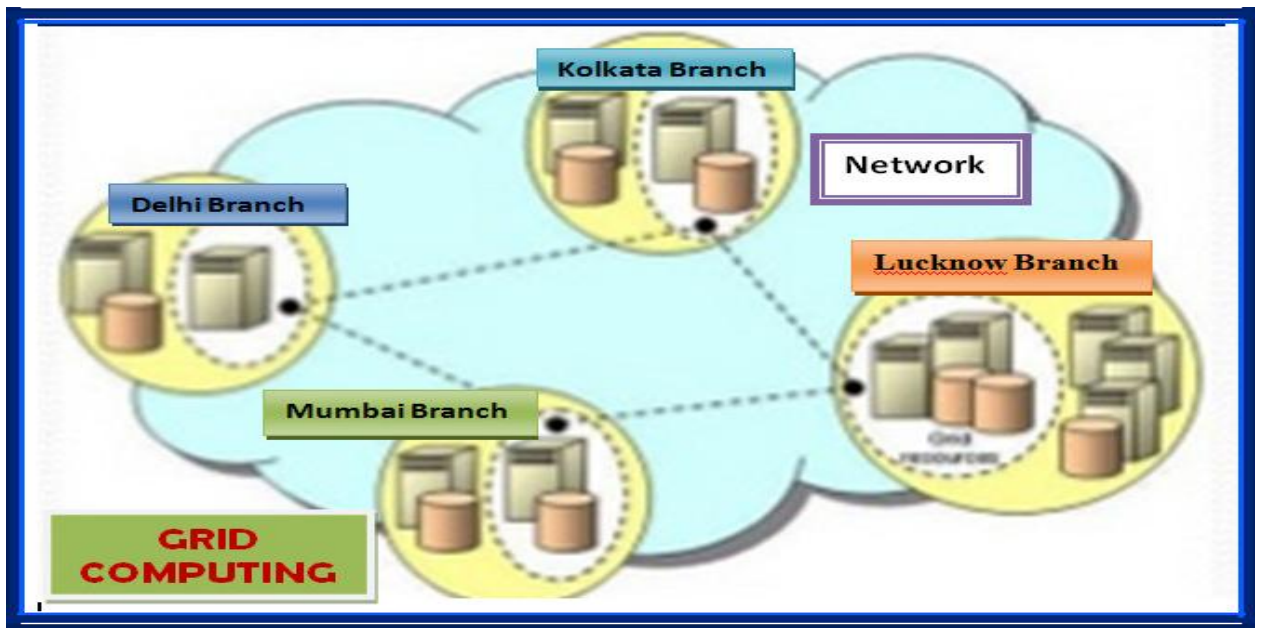

Fig.6 Cloud Computing

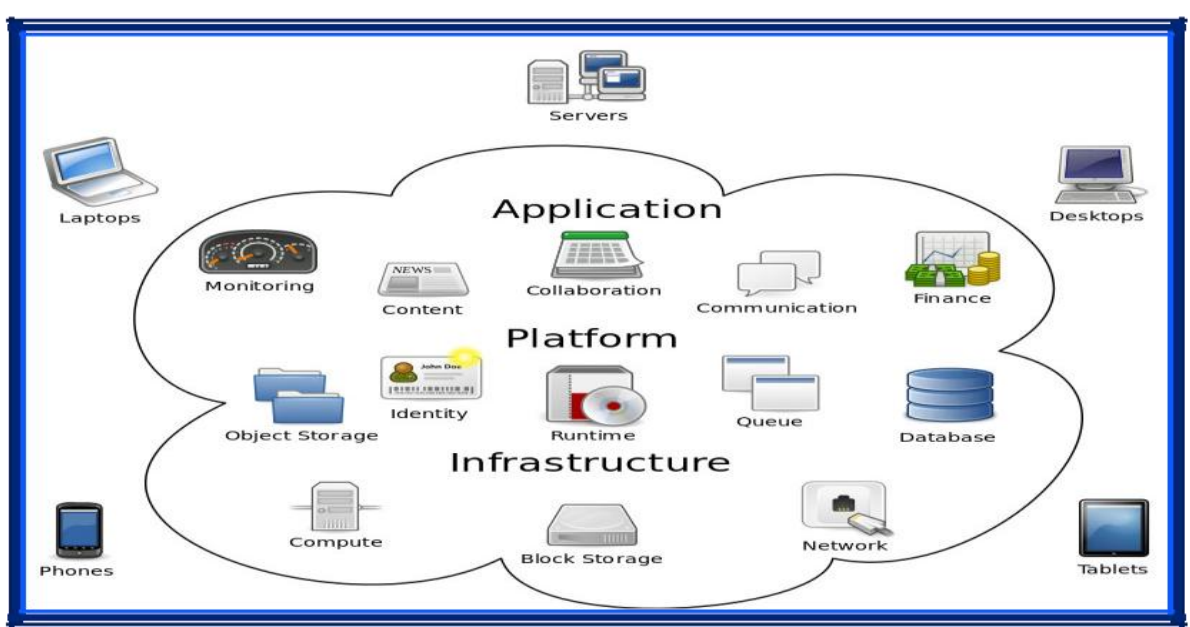

Fig.7 Deployment models

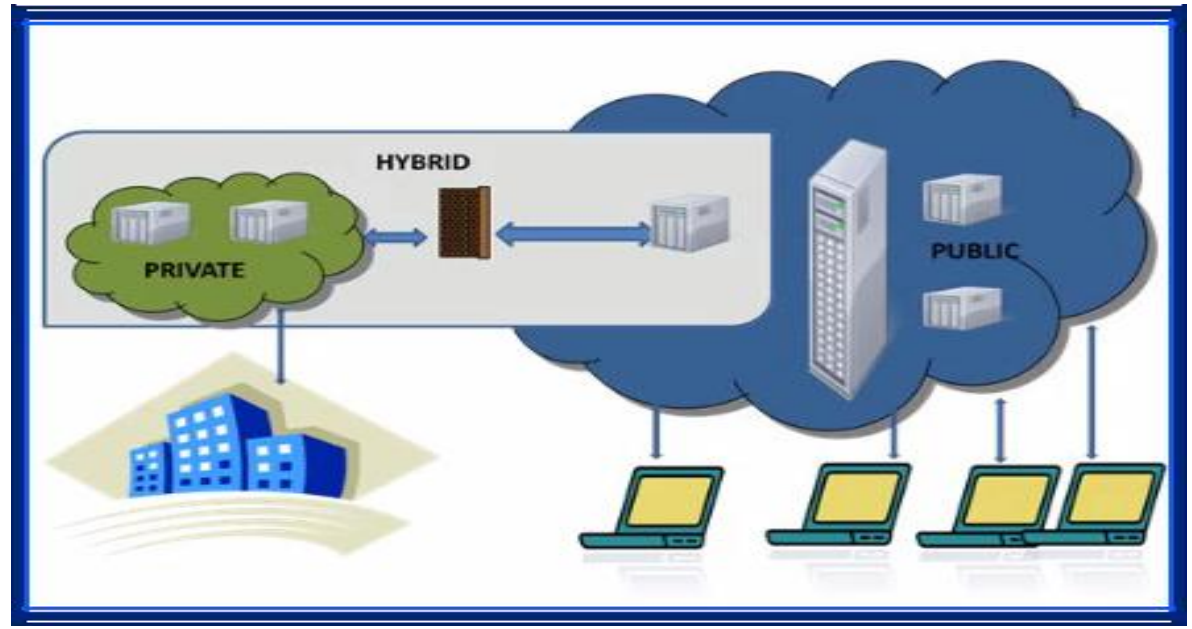


Fig.8 Cloud services model

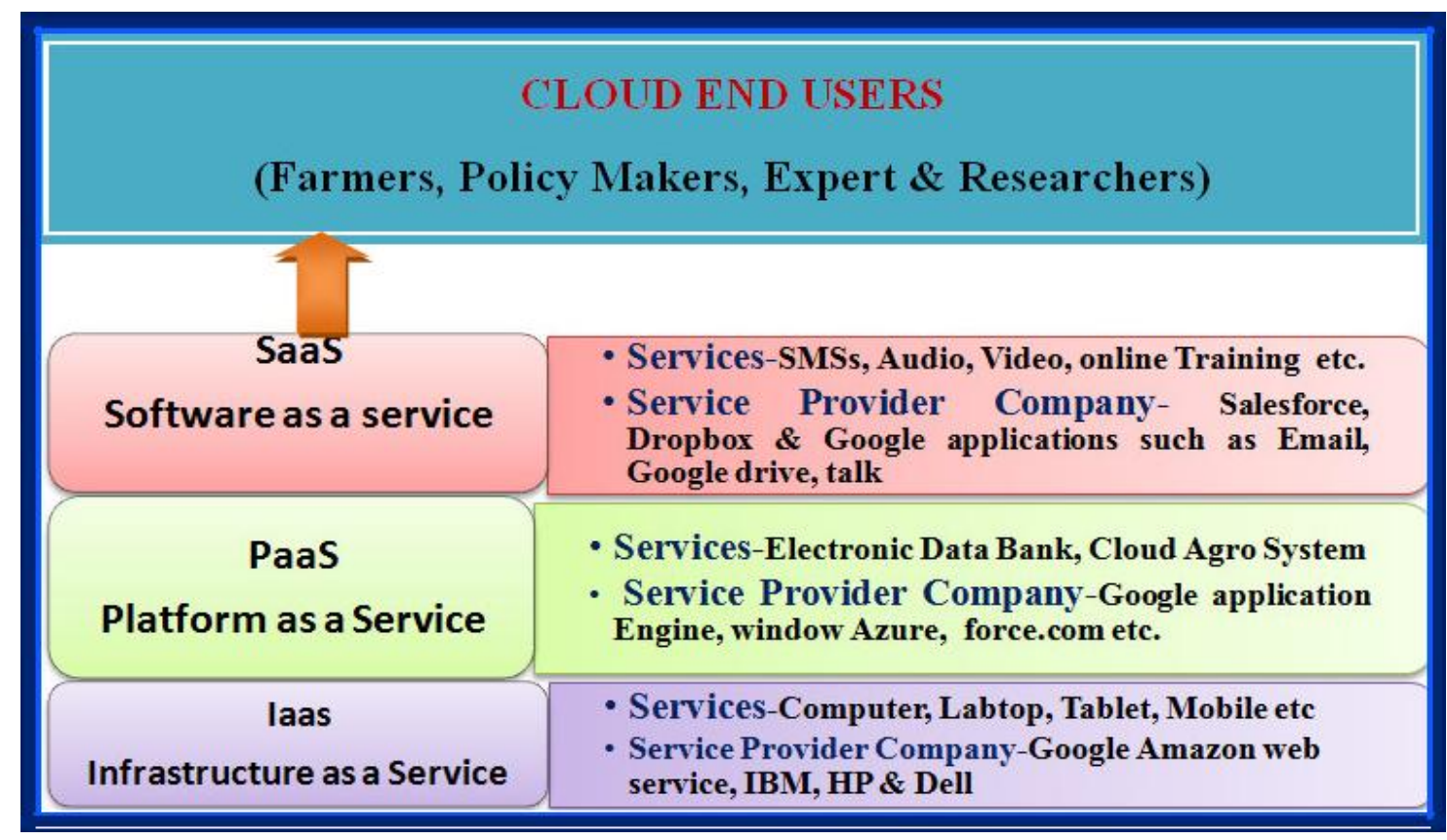

Benefits of cloud computing in agriculture

Data Readiness any time and any where Local and global communication Improve economic condition of the Nation Enhanced the GDP of the nation

Ensure food security level

Motivation of farmers and researchers

Reduction of technical issue

Rural-Urban movement

Data availability at any time and at any location without delay Improve market price of Food, seeds, other product

\section{Challenge of cloud computing in agriculture}

Maintenance and Supervision by third party, So data security is less

Indirect administrator accountability

Farmer is unknown for cloud computing technology

Less physical control

Attraction to hackers
Need on the network connectivity

Requires a constant Internet connection

Platform facility is not easily available for farmers

Farmers training necessary for this technology Does not work well with low-speed connections

it runs the risk of security

It is concluded as this prominent technique may deliver the agriculture-based knowledge along with management of natural resources and knowledge directly to the consumers not only in a small region like in nonstop marketing or shops but also in a wider region. This will change the whole supply chain, which is mainly in the hand of large companies, now, but can change to a more direct, shorter chain between producers and consumers. Cloud computing technology, applicable for the improvement of agriculture growth, food, grain, product, economic condition, Ensure food safety, GDP of the nation and circulate information related to agriculture etc. 


\section{References}

Azikiwe, A. I. (2012). The quality of extension education delivery among livestock farmers in Central Eastern Cape. Department of Agriculture, University of Hort Hare, Alice 5700, South Africa

Choudhary, S. K., Suman, R., Gupta, N., (2014) "Designing the Process of Stores Management for Implementing ERP in Manufacturing Organization: Case Study," Industrial Engineering Letters, International Institute of Science Technology \& Education, Vol.4, No.3, pp.49-66.

Choudhary, S.K., R.S. Jadoun; Mandoria, H.L; Kumar, A. (2014) "Latest development of cloud computing technology, characteristics, challenge, services \& applications", IOSR Journal of Computer Engineering, Volume 16, Issue 6, Ver. V (Nov Dec. 2014), pp. 57-68.

Choudhary, S.K; Gupta, N. (2014) "Developed the Inventory Management System for ERP Implementing in Manufacturing Industry", International organization of scientific Research Journal of Mechanical \& Civil Engineering Volume 11, Issue 6 Ver. VI (NovDec. 2014), PP 19-29

Hori, M., Kawashima, E. and Yamazaki, T., (2010) "Application of cloud computing to agriculture and prospects in other fields", Fujitsu Science and Technology Journal, Vol.46, No.4, pp.446-454.

Hori, M., Kawashima, E. and Yamazaki, T., 2010, "Application of cloud computing to agriculture and prospects in other fields", Fujitsu Science and Technology Journal, Vol.46, No.4, pp. 446-454.

Jayade, K. G. and Gaikwad, C. J. (2013)
"Cloud Computing for Agricultural Information Management in India", International Association of Scientific Innovation and Research, Vol. 6, No.1, pp. 38-42

Jianxun Zhang, Zhimin Gu and Chao Zheng (2010) "A Summary of Research Progress on Cloud Computing", Application Research of Computers, Vol. 27, No. 2, 429-433.

Kamath, S. and Chetan, A.A. (2011) Affordable, interactive crowd sourcing platform for sustainable agriculture: Enabling public private partnerships. Cloud Computing Journal, April, 2011.

Kun Qian (2012) "The Application of Cloud Computing in Agricultural Management Information System", Hubei Agricultural Sciences, Vol.5, No.1, 159-162.

Madhu, B. M., (2010), Technological gap in turmeric production practices in Belgaum district. M. Sc. (Agri.) Thesis, Univ. Agric. Sci., Dharwad, Karnataka (India).

Patel, R. and Patel, M. (2013) "Application of Cloud Computing in Agricultural Development of Rural Indiall", International Journal of Computer Science and Information Technologies, Vol. 4, No.6, pp. 922926.

Quan Chen, and Qianni Deng (2009) "Cloud Computing and Its Key Technologies", Journal of Computer

Rabi Prasad Padhy, Manas Ranjan Patra, Suresh Chandra Satapathy, "Cloud Computing: Security Issues and Research Challenges", IRACST Applications, Vol. 29, No. 9, 256.

Rani, S. and Gangal, A. (2012) "Security issues of banking adopting the application of cloud computing", International Journal of Information Technology and Knowledge 
Management, Volume 5, No. 2, pp. 243-246.

Suman, R., Choudhary, S.K., Preet, P., (2014)

"Computer Govern Maintenance System for a Process Industry," Computer Engineering and Intelligent Systems, IISTE, Vol. 5, No.3, pp.1724.
Thompson, F. T. (2011). Swaziland Business Year Book. Christina Forsyth Thompson, Mbabane-Swaziland.

Wenshun Cui (2011) "Application and Developing Prospect of Cloud Computation in the Agricultural Informationization", Agricultural Engineering, Vol. 2, No. 1, 40-43

\section{How to cite this article:}

Deepak Indoria and Deepa Indoria. 2019. Interrelation between Cloud Computing Technology and Agriculture Fields. Int.J.Curr.Microbiol.App.Sci. 8(1): 2991-2999.

doi: https://doi.org/10.20546/ijcmas.2019.801.318 